Policy Research Working Paper 1655

\section{Uncertainty and the Price for Crude Oil Reserves}

\section{Timothy J. Considine}

Domald F. Larson
Returns to storage for crude oil reserves contain both a costreducing component fconsistent with Kaldor's original notion of "convenience" 1 and ofter sizable premiums associated with the dispersion of petroleum prices.

The World Bank

International Economics Department Commodity Policy and Analysis Unit 
Policy Research Working Papek 1655

\section{Summary findings}

Innovations in futures, options, and derivative instruments permit active trading, speculating, and hedging - linking markets for phrsical petroleum products with financial markets. These derivative markets continuously value petroleum delivered today and for future dates, thus providing a market price for inventories. Underground petroleum reserves are also an inventory defined by exploration survey's and development drilling. As a result, observahle market information can be used to value these reserves.

Option-valuation models can be used to price reserves using observable markets, but are dependent on unexplained convenience yields revealed by the term structure of futures prices. Considine and Larson apply a general model of inventory pricing to perroleum inventories and generate an empirical model of the returns to storage for petroleum markets. They examine the determinants of the convenience yield for crude oil using a stochastic control model.
They specify optimal production and inventory conditions using a third-order cost function and estimate them using monthly observations. Their inventory arbitrage condition embodies the Hotelling principle and Kaldor's convenience yield, and includes a premium on the dispersion in crude oil prices.

The empirical results suggest that returns to storage contain both a cost-reducing component (consistent with Kaldor's original notion of "convenience") and often sizable premiums associated with the dispersion of petroleum prices. Their findings suggest that crude oil markets differentiated by quality and location provide similar premiums.

The premiums associated with the dispersion of petroleum prices may account for persistent backwardation in crude oil prices. This finding may also explain the wide discrepancies between Hotelling values and transaction prices found in previous studies.

This paper - a product of the Commodity Policy and Analysis Unit, International Economics Department — is part of a larger effort in the department to further the understanding of resource pricing and commodity markets. The study was funded by the Bank's Research Support Budget under the research project "Uncertainty and the Price of Crude Oil Reserves" (RPO 679-23). Copies of this paper are available free from the World Bank, $1818 \mathrm{H}$ Street NW, Washington, DC 20433. Please contact Pauline Kokila, room N5-030, telephone 202-473-3716, fax 202-522-3564, Internet address pkokila@worldbank.org. September 1996.(18 pages)

The Policy Research Working Pafer Serics disseminates the findings of work in progress to encourage the exchange of ideas about development issues. An objective' the series as to get the findings out quickly, even if the presentations are less than fully polished. The papers camy the names of the authors and should be used and cited accordingly. The findings, interpretations, and conclusions are the authors' own and should not be attrabuted to the World Bank, its Executive Buard of Directors, or any of its member countries. 


\section{Uncertainty and the Price for Crude Oil Reserves}

by

Timothy J. Considine

and

Donald F. Larson

The authors are Associate Professor in the Department of Mineral Economics at The Pennsylvania State University and Economist in the International Economics Department at the World Bank. The authors would like to thank M. A. Adelman, T. Akiyama, T. Malliaris, and G. C. Watkins for their helpful comments. The research was funded under RPO 679-23. 


\section{Table of Contents}

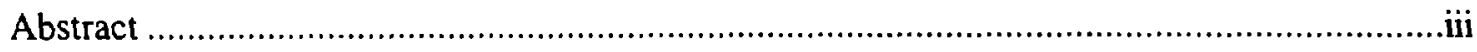

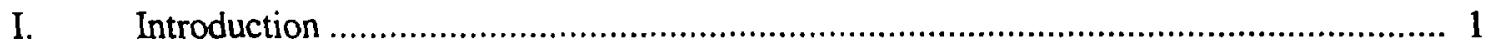

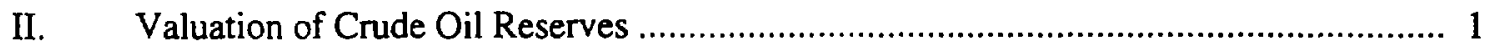

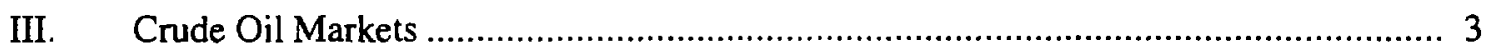

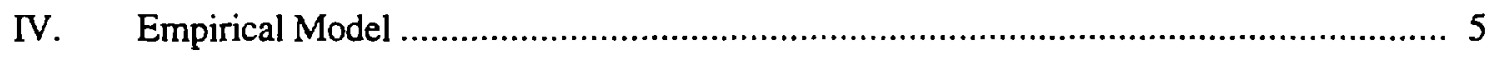

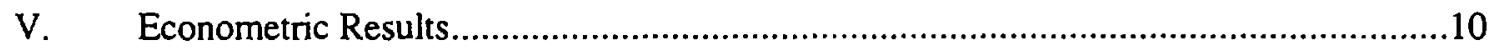

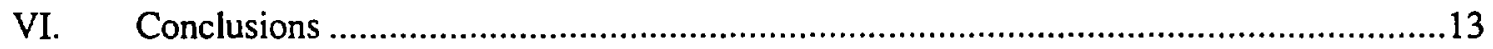

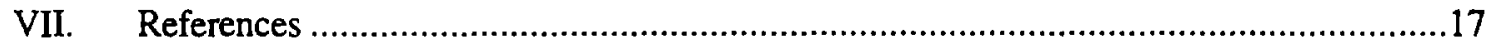

Tables

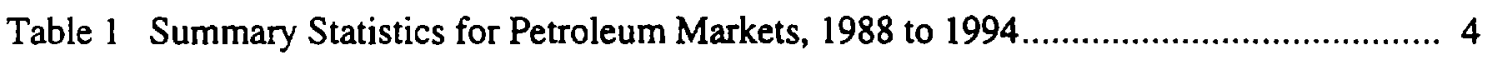

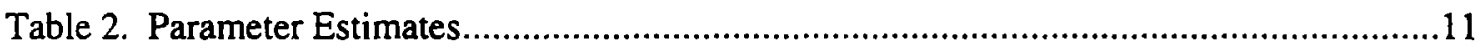

Table 3. Elasticities and Scaled Derivatives...................................................................11

Table 4. Estimated Dispersion Premiums for Various Crude Oils ....................................13

\section{Figures}

Figure 1. Prices for West Texas Intermediate Crude Oil, 1988-1994.................................. 14

Figure 2. Crude Oil Inventories in the United States, 1988-1994 ........................................ 14

Figúre 3. Implied Volatility in Crude Oil Options, 1988-1994 .......................................... 15

Figure 4. Inventories and the Four Week Forward Spread.............................................. 15

Figure 5. Estimated Cost Reducing Effect of Stocks ...................................................... 16

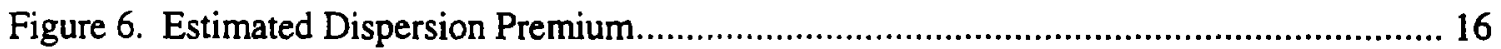




\section{Introduction}

Innovations in futures, options, and derivative instruments permit active trading, speculating, and hedging linking markets for physical petroleum products with financial markets. These derivative markets continuously value petroleum delivered today and for future dates, thereby providing a market price for inventories. Underground petroleum reserves are also an inventory defined by exploration surveys and development drilling. As a result, observable market information can be used to value these reserves.

Option-valuation models can be used to price reserves using observable markets, but are dependent upon unexplained convenience yields revealed by the term structure of futures prices. This paper applies a general model of inventory pricing to petroleum inventories and generates an empirical model of the returns to storage for petroleum markets. The results suggest that the retums contain both a cost-reducing component consistent with Kaldor's original notion of "convenience" as well as a frequently sizeable premium associated with the dispersion of petroleum prices. Further, our findings suggest that crude oil markets differentiated by quality and location provide similar premia.

The valuation of crude oil reserves raises a number analytical issues, which we identify and explore in the following section. To set the stage for our empirical analysis, we then provide an overview of crude oil markets. Our empirical results appear in section five after presentation of the empirical model. The paper concludes with a summary of our main findings and suggestions for further research.

\section{Valuation of Crude Oil Reserves}

Hotelling (1931) proposed that the equilibrium rate of retum on an exhaustible natural resource will rise at the rate of interest. The logic is that in equilibrium the producer is indifferent between holding a barrel of oil in reserve and producing one barrel now when the rate of appreciation on the reserve is just equal to the rate of return from pumping now and investing the proceeds.

There have been several empirical studies to test the validity of the Hotelling Principle. Time series studies by Heal and Barrow (1980) and Smith (1981) generally have not been supportive although the tests and data have serious difficulties. Miller and Upton (1985a) test a related relation, called the Hotelling Valuation Principle (HVP), in which the value of mineral reserves depends upon prices net of extraction costs. They find that the Hotelling values account for a significant portion of the variation in market values but in a later study Miller and Upton (1985b) find less support for the HVP.

Adelman (1990) argues that the valuation principle is not useful because it implies unrealistically high depletion rates. Moreover, Adelman (1990) asserts that there is really no fixed economic stock of petroleum resources, only flows into a reserve inventory. Later, Adelman and Watkins (1995) use actual transactions prices for oil and gas properties and find that their estimates of reserve values are less than half 
those suggested by the HVP. These results support Adelman's (1990) previous suggestion that such a discrepancy might arise because the buyer is paying for the option to more intensively develop a known oil pool sometime in the future.

An altemative approach to pricing petroleum assets has its roots in the literature on the cost of storage. Kaldor (1939), Working (1934), Brennan (1958) and Telser (1958) argue that inventory holding is profitable even during price backwardation due to a convenience yield that offsets the negative returns from storage. Starting with Kaldor, a number of authors attributed the convenience yield to cost-reducing features of inventory holding. However, more recently, the discussion on the value of inventories has emphasized other attributes. Lovell (1961) suggested that inventories serve to smooth production. This notion has been tested empirically with mixed results by Blinder $(1982,1986)$, Fair (1989), Krane and Braun (1991), and Blinder and Maccini (1991). Williams and Wright (1990) emphasize the retums to storage due to potential stockouts and Considine (1991) and Pindyck (1994) stress the non-linear relationship between production and storage costs.

Brennan and Schwartz (1985) and later Gibson and Schwartz (1990) sought to derive the market price for pricing petroleum assets based on the observable term structure of petroleum futures markets. Although motivated by the time series properties of the forward convenience yield of crude oil (Gibson and Schwartz, 1989), Gibson and Schwartz (1990) developed an empirical model of pricing assets which explicitly modeled a risk-premium based on stochastic price movements. Later, Larson (1993) provided a stochastic model and derived a price arbitrage equation from first principals to explain the negative returns to storage for refined copper.

In this paper, we stress that measures of the convenience yield contain two separate components. First, inventories may be cost-saving in the tradition of Kaldor. Second, the value of inventories embodies a premium related to the stochastic nature of prices, similar to the value of an option. The value of this premium can be derived from observed market information. We conclude that, on average, $40 \%$ of the value of US petroleum inventories can be attributed to the volatile nature of petroleum prices. The premia are also substantial for UK Brent-38b and Dubai Fateh Prompt crude oil and smaller for Malaysia Tapis and Indonesia Minas-34 crudes. 


\section{Crude Oil Markets}

Once crude oil is extracted from the earth, it is collected by pipelines at the oil field and then shipped either by pipeline or tanker to refineries where it is refined into an array of petroleum products, including gasoline, distillate fuel, residual fuel oil, jet fuel, and petrochemical products. Despite the perceived dominance of the Organization of Petroleum Exporting Countries (O. P. E. C.), many countries around the world now produce crude oil. The United States is the most mature producing area with extensive trading in crude oil futures and options. Many developing countries, such as Columbia, Mexico, and Malaysia, have become significant crude oil producers in recent years.

Inventories of crude are held at various points in the petroleum distribution network. A small amount is held by oil lease holders at the oil field. The largest stocks, nearly two-thirds of total private stocks in the U.S., are in pipelines and tank farms. The remaining third of private stocks are held at petroleum refineries. In the U.S. almost 50 percent of total stocks are held by the federal government in the strategic petroleum reserve. In this study, we ignore these stocks because they do not vary with market conditions. Moreover, we examine total private stocks because Blanchard (1983) shows that basic arbitrage relations are unaffected by aggregation over the distribution chain. We measure stocks and flows in physical units unadjusted for seasonal variation, which avoids the measurement errors identified by Fair (1989).

Although extensive price data exist for several regions around the world, monthly inventory and production data for developing countries is much more difficult to obtain. As a result, we confine our initial investigation of the determinants of the convenience yield for crude oil to the United States. We then use these results to estimate dispersion premium for other crudes traded around the world.

Crude oil production in the United States averages 7.36 million barrels per day (see Table 1). Total private crude oil inventories are on average about 340 million barrels with a standard deviation of fourteen million barrels. Variability in domestic production is slightly less than the variability in domestic crude oil sales, which may reflect production smoothing.

Spot prices for West Texas Intermediate (WTI) and several other major crudes appear in Table 1. Forward contracts are actively traded in oil so we use the four week forward price in computing convenience yields. ${ }^{1}$ The convenience yields are identical reflecting highly integrated global markets.

Time series plots for crude oil prices and inventories appear in the following two figures. Both plots reveal no clear trend in prices and inventories over this period. However, both display sharp swings

\footnotetext{
' As Pindyck (1994) notes, unlike forward contracts, futures require a settlement and transfer of funds at the close of each trading day. As a result, oil futures prices exceed forward prices if the risk free interest rate is stochastic and positively correlated with spot crude oil prices.
} 
before and after August 1990, when the Persian Gulf crisis started. Before the crisis, spot crude prices were falling and inventories were increasing. Spot sales were selling at a deep discount relative to forward sales so it was cheap to hold inventories. With the onset of the crisis, spot prices shot above forward prices, holding inventories became very expensive and, as a result, stock levels declined sharply (see Figures 1 \& 2). Also during this period, implied volatility on crude oil options increased sharply as Figure 3 illustrates.

The relationship between storage levels and the forward price spread is illustrated in Figure 4.

Here we see that large negative spreads occur when the market is in backwardation with spot prices exceeding the forward prices. These negative returns occur at relatively low stock levels. In contrast, large positive forward spreads occur with high inventory levels, which depress spot prices. The scatter diagram also reveals that the crude oil market is often in price backwardation.

Table 1: Summary Statistics for Petroleum Markets, 1988 to $1994^{2}$

\begin{tabular}{lcr}
\hline & Mean & $\begin{array}{c}\text { Standard } \\
\text { Deviation }\end{array}$ \\
\hline U. S. Crude Oil & Millions of Barrels) & \\
Dailv Production & 7.36 & 0.45 \\
Dailv Sales & 7.37 & 0.52 \\
Ending Stocks & 341.00 & 14.17 \\
& & \\
Spot Prices & (Dollars per Barrel) & \\
West Texas Intermediate Crude & 19.77 & 3.75 \\
Malavsia Tapis & 19.61 & 4.26 \\
Dubai Fateh Prombt & 16.16 & 3.64 \\
UK Brent-38 b & 18.63 & 4.19 \\
Indonesia Minas-34 & 18.48 & 4.09 \\
& & \\
Four Week Forward Prices & 19.63 & 3.56 \\
West Texas Intermediate Crude & 16.02 & 3.39 \\
Dubai Fateh & 18.47 & 3.90 \\
UK Brent-38 b & & \\
& (Percent) & \\
Convenience Yields* & 5.96 & 2.24 \\
West Texas Intermediate Crude & 5.96 & 2.31 \\
Dubai Fateh & 5.96 & \\
UK Brent-38b & & \\
\hline
\end{tabular}

\footnotetext{
${ }^{2}$ These yields are computed as yield $d_{i}=r+12\left[\ln \left(P_{i t+1}\right)-\ln \left(P_{i t}\right)\right]$ where $\mathrm{r}$ is the yild on a one-month certificate of deposit at an annual rate and $P_{i r}$ is the spot price of oil and $P_{i t+1}$ is the forward price.
} 


\section{Empirical Model}

In this section, the formal model is presented ${ }^{3}$. A generalized price-arbitrage condition is derived from the first-order conditions of the optimization problem which is consistent with inventory-holding during an anticipated price fall. The problem is characterized as a continuous two-cycle problem with uncertain future demand. In the current period, the producer knows the current sales price. By deciding how much to produce and sell, he determines how much inventory he will bring into the next period. The expected marginal value, or the shadow price, of the inventory in the next period is not known, but contains a stochastic element since demand is uncertain. The effects of random demand shocks on the shadow price of inventories may be asymmetric - that is, a positive random shock may increase prices by more than an equally sized negative random shock. In such a case, the shadow price of inventory will carry a dispersion premium so that the shadow price of inventories increases with the variance of the stochastic component of sales. Such a premium is analogous to the volatility premium in an options price and can result in positive inventory levels even when price declines are expected.

When sales contain a random element, inventory levels will also be stochastic and changes in inventories will contain a planned and unplanned component. The difference between planned and actual inventories will be the difference between expected and actual production minus sales. For the moment, assume that the change in inventories can be expressed as the following process:

$$
x_{t}-x_{t-1}-E_{t-1}\left[x_{t}-x_{t-1}\right]=\varepsilon_{t}=x_{s}-x_{t-1}-E_{t-1}\left[y_{t}-s_{t}\right]
$$

where $\varepsilon$ has an expected value of zero and a variance $\sigma^{2}$. Rewriting the constraint on inventories in continuous-time notation, the value of ending inventories at time $t_{l}$ is the solution to the following infinitehorizon problem:

$$
e^{-n t} V\left(x_{t l}\right) \equiv \operatorname{Max}_{s, y} E \int_{\|}^{\infty}\left\{[p s-C(y, x)] e^{-r(t-t)}\right\} d t, s . t . d x=E(y-s) d t+\sigma d v .
$$

The term $d v \equiv u(t) d t^{1 / 2}$ is a Wiener process, where $u(t) \sim N(0,1)$. Because inventory changes include a random component, $d x / d t$ does not exist in the usual sense and the rules of stochastic calculus apply.

Evaluated at $t_{1}$, the solution to (2) gives the value of ending stocks, that is, $J\left(x_{1}, t_{1}\right)=V\left(x_{1}\right) e^{-r t}$. In the language of optimal control theory, the firm's problem is a stochastic infinite-horizon problem, stretching from $t_{l}$ onwards. As a result, the shadow price for the end-of-period inventories in the first stage of the

\footnotetext{
'For a more detailed description of the model derivation, see Larson (1993).
} 
producer problem is based on expectations of an on-going process of production amid uncertain demand. Generally, the solution for $J\left(x_{i}, t_{l}\right)$ can be found by solving Bellman's equation, a partial differential equation: $-\partial J\left(x_{1}, t_{1}\right) / \partial t=r V\left(x_{1}\right) e^{-r t}$. Arbitrarily setting $t_{1}=0$ simplifies the equation somewhat so that the solution to the inventory problem from $t$, onward can be represented by the Hamilton-Jacobi equation of dynamic programming:

$$
r V_{(x l)}=\operatorname{Max}_{s, y} E[p s-C(y, x)]+V_{x}(y-s)+\frac{1}{2} v_{x x} \sigma^{2}
$$

The first-order conditions for the maximization of (3) are:

$$
\begin{gathered}
\text { i) } E\left(p-V_{x}\right)=0 \\
\text { ii) } E\left(-C_{y}-V_{x}\right)=0 \\
\text { iii) } E(d x)=E(y-s) d t \\
\text { iv) } x\left(t_{1}=0\right)=x_{1}
\end{gathered}
$$

The producer solves for planned production, sales and inventories by setting expected marginal costs equal to expected price equal to the shadow price of inventories, $V_{x}-$ which is itself an expected value.

It is worth noting that the distribution of the error term, especially $\sigma^{2}$, is independent of the decision variables. The variance of the error is regarded as a state of nature and is not subject to choice on the part of the producer. This assumption is implicit throughout the paper and works well empirically.

Several additional assumptions must be made to guarantee that the first-order conditions do indeed provide a maximum. $V$ must be concave in $x$; the solution values of $x, y$, and $s$ must be positive ${ }^{4}$ (otherwise border solutions must be considered); and the transversality-at-infinity condition must hold. ${ }^{5}$

\footnotetext{
${ }^{4}$ For the empirical problem at hand, refiner inventories of refined copper are all positive as are quantities sold and produced. Inventories at both the COMEX and LME have remained positive throughout the history of those institutions as well. However, to be complete, stock-outs need to be considered in the theoretical model and nonnegativity constraints introduced to the maximization problem. These are given in Annex 2.

'For the infinite-horizon autonomous problem given above, the transversality condition is: $\lim _{t \rightarrow \infty} V_{z}(t) z(t) e^{-r\left(t-t_{0}\right)}=\lim _{i \rightarrow \infty} J_{i}(t) z(t) e^{-r t}=0$.

Benveniste and Scheinkman (1982) showed that the condition is necessary and sufficient for the solution of A1.6 to be optimal. The logic is that any positive stock level must have no value as the problem approaches infinity. Otherwise, the firm could further increase profits by either producing less or selling more in the last period. Inventories have value because, ultimately, they can be sold. If some price exists at which no copper can be sold, then some upper bound must exist for the shadow price of inventories. If so and if stock levels, $x$, are limited by physical storage or natural endowments, then discounting will assure that the transversality condition holds. See Brock (1987) for further details on the general condition.
} 
An expression for the marginal value of inventories is found by applying the envelope theory (Dixit, 1990) to the Hamilton-Jacobi equation given in (3):

$$
r V_{x}=E\left[-C_{x}+V_{x x}(y-s)+\frac{1}{2} V_{x x x} \sigma^{2}\right]
$$

At the solution, $E[p]=V_{x}$, (as part of the first-order conditions in (4) so that:

$$
E[d p / d t]=V_{x t} E[d x / d t]
$$

Rewriting part iii of (4) provides $E[d x / d t]=E[y \cdot s]$. These results can be combined to form a pricearbitrage condition. First, from rearranging (6) and using iii from (4):

$$
V_{x x} E[y-s]=V_{x x} E[d x / d t]=r V_{x}+E\left[C_{x}\right]-\frac{1}{2} v_{x x x} \sigma^{2}
$$

Combining (6) with (7) provides:

$$
E[d p / d t]=r E[p]+E\left[C_{x}\right]-\frac{1}{2} V_{x x x} \sigma^{2}, \text { for } x s y>0
$$

Equation (8) is a generalization of price-arbitrage conditions given in cost-of-carry models such as Williams and Wright (1991, p. 27). The arbitrage condition states that the expected change in price will be equal to $r E[p]$-- interest on investing the money elsewhere -- plus $C_{x}$-- the costs of physical storage and any amenity from storage -- minus $\frac{1}{2} V_{x e r} \sigma^{2}$. If $V_{x u r}$ is positive, then this last term constitutes a dispersion premium that increases with the variability of the stochastic component of inventories ${ }^{2}$. The last two components of (8) have important implications for holding inventories in the face of less-than-full carrying charges. According to the condition, it still may be optimal to hold inventories when the market is in backwardation -- $E[d p / d t]<0$-- if inventories provide a cost-reducing Kaldor-convenience (that is, if $C_{x}$ is sufficiently negative) and/or the dispersion premium, $\frac{1}{2} v_{m z} \sigma^{2}$, is sufficiently positive. The two components are not mutually dependent. Kaldor-convenience alone can potentially explain inventoryholding in backward markets, as can a dispersion premium. When $V_{s x}=0$ and $C_{x}$ is positive, (8) can be intrepreted either as the cost-of-carry arbitrage condition from the literature on inventories, or as the Hotelling Principle without extraction costs. 
Two of the results of the model can be used to derive an econometric estimate of the dispersion premium. Combining i) and ii) from (4) states that expected price is equal to marginal cost:

$$
E(p)=E\left(C_{y}\right)
$$

This result along with the price-arbitrage equation (8), are given functional form to derive empirical results.

To implement the model of crude oil prices and inventories given by equations (8) and (9), we approximate the cost function with a third order quadratic function:

$$
C=\alpha+\sum_{i=1}^{5} \alpha_{i} X_{i}+\frac{1}{2} \sum_{i=1}^{5} \sum_{j=1}^{5} \beta_{i j} X_{i} X_{j}+\frac{1}{6} \sum_{i=1}^{5} \sum_{j=1}^{5} \sum_{k=1}^{5} \gamma_{i j k} X_{i} X_{j} X_{k}
$$

where

$$
\begin{array}{lll}
X_{1} & = & \text { wages, } \mathrm{w}, \\
X_{2}= & \text { field production of crude oil, } \mathrm{y}, \\
X_{3}= & \text { month ending private stocks of crude oil, } \mathrm{x}, \\
X_{4}= & \text { oil wells drilled, } \mathrm{k}, \text { and } \\
X_{5}= & \text { technical change index, } \mathrm{z} .
\end{array}
$$

We assume symmetry in $\beta_{i j}$ and $\gamma_{i j k}$. In addition to production and ending inventories, we assume the cost function depends upon wage rates, production capacity, and technical change. This function represents the cost of producing, transporting, and delivering crude oil to the wholesale market, where the buyers are crude oil traders and refiners. We assume that production and inventories jointly determine costs. Due to data unavailability, drilling activity is used as a proxy for production capacity because drilling typically increases sharply as production capacity limits are approached. Likewise, we must use a proxy for technical change. Since the late 1980s there have been major advances in oil exploration and development, including seismic imaging, automatic positioning of rigs in deep water, and horizontal drilling. As a result, the efficiency of oil and gas production has increased substantially. The only readily available proxy for these changes is the success rate in drilling measured by the ratio of discoveries per well drilled, which serves as our proxy for technical change, $z$.

The third order cost function implies that marginal cost, $C_{y}$, and the partial derivative of cost with respect to inventories, $C_{x}$, are quadratic functions:

$$
\frac{\partial C}{\partial X_{i}}=\alpha_{i}+\sum_{j=1}^{s} \beta_{i j} X_{j}+\frac{1}{2} \sum_{j=1}^{s} \sum_{k=1}^{s} \gamma_{j i k} X_{j} X_{k}, i=y, x
$$


Our cost function implies that the third order derivatives in the dispersion premium are parameters. The expected marginal cost equation takes the following form:

$$
\begin{aligned}
P= & \alpha_{y}+\beta_{w y} w+\beta_{y y} y+\beta_{y x} x+\beta_{y k} k+\beta_{y z} z \\
& +(1 / 2) \gamma_{w y y} w^{2}+\gamma_{w y y} w y+\gamma_{w y x} w x+\gamma_{w y k} w k+\gamma_{w y z} w z \\
& +(1 / 2) \gamma_{y y} y^{2}+\gamma_{y y x} y x+\gamma_{y y k} y k+\gamma_{y y z} y z \\
& +(1 / 2) \gamma_{y x x} x^{2}+\gamma_{y x k} x k+\gamma_{y x z} x z \\
& +(1 / 2) \gamma_{y k k} k^{2}+\gamma_{y k z} k z+(1 / 2) \gamma_{y z z} z^{2}
\end{aligned}
$$

where we have replaced the numbered subscripts with letters used in (3) above. The estimating equation for the arbitrage relation is as follows:

$$
\begin{aligned}
p f-p-r p & =\alpha_{x}+\beta_{w x} w+\beta_{y x} y+\beta_{x x} x+\beta_{x k} k+\beta_{x z} z \\
& +(1 / 2) \gamma_{w w x} w^{2}+\gamma_{w y x} w y+\gamma_{w x x} w x+\gamma_{w x k} w k+\gamma_{w x z} w z \\
& +(1 / 2) \gamma_{y y x} y^{2}+\gamma_{y x x} y x+\gamma_{y x k} y k+\gamma_{y x z} y z \\
& +(1 / 2) \gamma_{x x x} x^{2}+\gamma_{x x k} x k+\gamma_{x x z} x z \\
& +(1 / 2) \gamma_{x k t} k^{2}+\gamma_{x k} k z+(1 / 2) \gamma_{x z z} z^{2} \\
& -(1 / 2)\left[\gamma_{y y}(d y)^{2}+2 \gamma_{y y x} d x d y+\gamma_{y x x} \sigma \frac{2}{x}\right]
\end{aligned}
$$

Using results from Cootner (1964) and Merton (1992), Larson (1993) shows that the volatility of inventories can be expressed in terms of the associated price volatility. We, therefore, use implied price volatility from the crude oil options market for $\sigma \frac{2}{x}$.. We use the difference between the 4 week forward price and the spot price for the expected price change in (6).

We append random error terms to (5) and (6) to represent expectational errors and estimate the two equations as a system using the Generalized Method of Moments (GMM) estimator. The GMM estimator is potentially superior to conventional instrumental variable estimators, yielding consistent and efficient estimators when past or future values of the instruments are correlated with the error terms. Our sample period starts in February 1989 and ends in June 1994. The petroleum production, sales, and inventory data are from the Energy Information Administration. Spot and forward prices are collected from Petroleum \& Energy Intelligence Weekly, Inc. Implied price volatility is from the Commodity Research Bureau.

The information set available to the oil market provides a basis for selecting instrumental variables. The instruments include lagged variables from the model, including spot and forward prices, wages, 
production, stocks, technical change, short term interest rates, drilling activity, and volatility. We supplement this list with demand shock instruments that include heating and cooling degree days and lagged, seasonally unadjusted values for the Standard and Poor 500 stock price index, housing starts, and industrial production. We also include dummy variables for fixed monthly effects, the Exxon Valdez tanker accident, the invasion of Kuwait in August 1990, "Desert Shield" from September through December 1990, and for "Desert Storm" during January and February 1991. These last three dummy variables represent the impact of political events on expectations in the oil market. All continuous variables are normalized except prices and the returns to storage to avoid scaling problems in estimating the model and in calculating elasticities.

\section{Econometric Results}

We first test the maintained restrictions of the model, such as dynamic optimization and the quadratic approximation of the cost function. The value of the objective function for the GMM estimator is distributed as a Chi-squared statistic with degrees of freedom in this study equal to the $\mathbf{3 0}$ instruments times 2 equations minus the 36 parameters. The value of the objective function is 13.4 , which is less than the critical value of 36.45 at the 5 percent level of significance with 24 degrees of freedom. Consequently, we cannot reject the over-identifying restrictions of the model. The fit of the two equations is reasonably good with the $\mathrm{R}^{2}$ coefficient 0.55 for marginal cost and 0.53 for the returns to storage equation. The estimated residuals do not have a unit root, which suggests the absence of serious dynamic mis-specification.

In Table 2, we present the parameter estimates. The first order effects of wages, production, drilling, and technical change are significant in the marginal cost equation. The "own" second-order coefficients for wages, inventories, drilling, and technical change in the marginal cost equation are also significant. Seven interaction parameters are also significant in the marginal cost equation: wages production, drilling with production and wages, and technical change with wages, production, inventories and drilling. The first order effects for stocks, wages, and technical change in the returns to storage equation are significant. Like marginal cost, the parameters on squared wages, stocks, drilling and technical change in the returns to storage relation are significant. Three second-order effects in $C_{x}$ are significant: wages with drilling and technical change, and drilling with technical change. The dispersion

term is a function of three parameters, $\gamma_{y y y}, \gamma_{y x x}, \gamma_{y x x}$. The last parameter, $\gamma_{y x x}$, is significantly positive and when multiplied by implied volatility is large enough so that the dispersion premium is also positive. 
Table 2: Parameter Estimates

\begin{tabular}{|c|c|c|c|c|c|}
\hline Parameter & Estimate & tStatistic & Parameter & Estimate & Statistic \\
\hline$\alpha_{v}$ & -3311.53 & -3.95 & $\gamma_{\text {vat }}$ & -86.14 & -3.11 \\
\hline$\beta_{w v}$ & 2557.83 & 3.8 & $\gamma_{\mathrm{vkz}}$ & -86 & -3.91 \\
\hline$\beta_{v v}$ & 2472.79 & 2.67 & $\gamma_{v z z}$ & -96.97 & -4.14 \\
\hline$\beta_{v x}$ & -258.13 & -1.01 & $\alpha_{x}$ & 240.05 & 1.14 \\
\hline$\beta_{v k}$ & 1098.17 & 5.01 & $\beta_{w x}$ & -280.06 & -1.84 \\
\hline$\beta_{\mathrm{vz}}$ & 728.93 & 3.67 & $\beta_{x x}$ & 175.76 & 2.32 \\
\hline$\gamma_{w w v}$ & -1303.71 & -4.38 & $\beta_{x k}$ & -25.08 & -0.75 \\
\hline$\gamma_{w v v}$ & -844.02 & -1.71 & $\beta_{x,}$ & -73.85 & -2.56 \\
\hline$\gamma_{\text {wox }}$ & 158.30 & 1.63 & $\gamma_{w w x}$ & 121.22 & 2.50 \\
\hline$\gamma_{w v k}$ & -424.78 & -5.50 & $\gamma_{\text {wrx }}$ & -56.51 & -1.38 \\
\hline$\gamma_{\text {wv? }}$ & -158.09 & -2.04 & $\gamma_{\text {wxk }}$ & 29.51 & 2.72 \\
\hline$\gamma_{v v v}$ & -683.01 & -1.33 & $\gamma_{w \times x}$ & 25.17 & 1.91 \\
\hline$\gamma_{v v x}$ & 39.15 & 0.24 & $\gamma_{x x x}$ & -82.09 & -2.04 \\
\hline$\gamma_{\text {vvk }}$ & -486.13 & -3.48 & $\gamma_{\text {xxk }}$ & -19.94 & -1.33 \\
\hline$\gamma_{v v z}$ & -418.78 & -3.07 & $\gamma_{x x z}$ & -11.34 & -1.50 \\
\hline$\gamma_{\text {vox }}$ & 1.08 & 3.50 & $\gamma_{\text {xkk }}$ & 14.75 & 2.76 \\
\hline$\gamma_{v x k}$ & -5.50 & -0.26 & $\gamma_{x k z}$ & 5.67 & 2.06 \\
\hline$\dot{y}_{\mathrm{vxz}}$ & 44.33 & 2.22 & $I_{x z 2}$ & 8.70 & 2.79 \\
\hline
\end{tabular}

The model has variable elasticities of marginal cost and of returns to storage, which are presented in Table 3. Since the benefits of stock holding can be negative, we do not divide these elasticities by predicted $C_{x}$. Instead, we multiply the derivatives by the level of the variable in the partial equilibrium differentiation.

Table 3: Elasticities and Scaled Derivatives

\begin{tabular}{lrr}
\hline Marginal Cost, $C_{y}$ & Elasticities & "t"Ratios \\
\hline Wages & 0.22 & 0.36 \\
Production & -1.10 & -1.10 \\
Inventories & -0.44 & -2.84 \\
Drilling & 0.16 & 1.00 \\
Technical Change & -0.55 & -3.22 \\
& & \\
Stock/Cost Benefit, $C_{x}$ & Scaled Derivatives & "t" Ratios \\
& & \\
\hline Wages & -1.03 & -0.62 \\
Production & -8.81 & -2.84 \\
Inventories & 5.33 & 2.93 \\
Drilling & 0.09 & 0.19 \\
Technical Change & 0.19 & 0.35 \\
\hline
\end{tabular}

The inventory elasticity of marginal cost is -0.44 with a relatively high " $t$ " statistic suggesting that marginal costs shift up (down) with lower (higher) inventories. This finding in conjunction with our positive and significant estimate for $\gamma_{y x r}$ suggests that the dispersion premium arises because marginal cost decreases (increases) with higher (lower) inventories at an increasing rate. We also find that recent 
advances in drilling and exploration technology have significantly reduced marginal cost. Our negative production elasticity of marginal cost suggests increasing returns but its relatively low $t$ statistic suggests that this may not be significant.

The scaled derivative of the estimated $C_{x}$ function with respect to inventory levels is positive and significant, consistent with the theory of storage. The predicted values of $C_{x}$ are plotted against inventory levels in Figure 5. The graph illustrates that at low inventory levels, the cost reducing effect of holding inventory is large and at high stock levels $C_{x}$ is positive indicating that costs actually rise with additional stocks. We also find that the $C_{x}$ function shifts up (down) with lower (higher) production. The $C_{x}$ function does not seem to be significantly affected by wages, drilling, or technical change. Overall, our estimates reveal that at least a portion of the returns to storage reflects the cost-reducing benefits from holding stocks.

The dispersion premium, which constitutes the other portion of the returns to storage, is plotted below in Figure 6. We express the dispersion premium as a percent of the crude oil spot price at an annual rate. Our estimate is on average nearly 40 percent with a standard deviation of almost 18 percent. Notice in Figure 6 that the premium reached over 100 percent at the height of the Gulf War crisis and fluctuates considerably. This uncertainty premium may help explain the gap discovered by Adelman and Watkins (1995) between transactions prices for oil and gas properties and prices implied by the Hotelling Valuation Principle.

These dispersion premium may vary with political, economic, and geophysical uncertainties. To assess this possibility, we estimate the same model for crude oil sold in the United Kingdom, Dubai, Malaysia, and Indonesia. Due to data limitations we only estimate the intercept terms, $\alpha_{y}$ and $\alpha_{x}$, and $\gamma_{y x x}$ in equations (5) and (6) and assume the remaining parameters for $C_{y}$ and $C_{x}$ are the same as those estimated above. The forward prices for Malaysian Tapis and Indonesia Minas-34 are unavailable. As a proxy, we use the forward price for the Dubai Fateh (DF) crude since both crudes are traded in Asia.

We find the dispersion premium for U. K. Brent oil nearly identical with West Texas Intermediate while those for Dubai, Malaysia, and Indonesia are somewhat lower. All premiums, however, are substantial, suggesting that a significant dispersion premium exists for crude oil assets. As a result, we conclude that, for the countries examined here, country risk is not a factor in explaining the premium in oil inventory pricing. ${ }^{6}$

\footnotetext{
'Using a different time period and different methodology, Gibson and Schwartz (1990) also found evidence of a premium related to the stochastic component of petroleum price movements. However for their study, the premium ranged lower, averaging around $4.5 \%$.
} 
Table 4: Estimated Dispersion Premiums for Various Crude Oils

\begin{tabular}{|lcc|}
\hline & \multicolumn{2}{c|}{ Annual Percent } \\
Wean & Standard Deviation \\
Dubai Fateh Prompt & 39.81 & 17.78 \\
UK Brent-38 b & 37.56 & 17.28 \\
Malaysia Tapis & 40.71 & 17.30 \\
Indonesia Minas-34 & 25.37 & 11.67 \\
\hline
\end{tabular}

\section{Conclusions}

This paper provides a theoretically consistent empirical model of the convenience yield. Using a stochastic control formulation, we show how production and inventories are related to spot and forward prices for crude oil. Our results show that apparent losses from holding crude oil stocks are offset by the benefits derived from inventories and by a significant dispersion premium that rises sharply during market disruptions. This finding is consistent with the lack of empirical support for Hotelling-based theories of natural resources pricing. Moreover, our results suggest that current methods of pricing reserves and related assets significantly undervalue those assets. Further, this result holds across several markets for petroleum differentiated by location and type of crude.

Evaluating an investment in an oil project involves a daunting array of unknowns. Traditional discounted cash flow analysis projects a stream of discounted net revenues. Petroleum engineering relations provide a basis for projecting expected production levels with a reasonable degree of accuracy. Crude oil prices, however, are much more difficult to predict. Frequently, available future prices are used to a point and some version of the Hotelling Principle is used to value more distant production. The practical consequence is that oil reserves are undervalued since such methods ignore the dispersion premia and Kaldor-convenience effects which jointly determine the observed term structure for forward and future prices.

Further research could reveal the robustness of this estimate. Our preliminary analysis yields plausible dispersion premia, but more complete information is needed. A cross sectional time series analysis for several oil producing countries could be useful. Finally, an examination of the demand for inventories could result in more efficient estimates. 

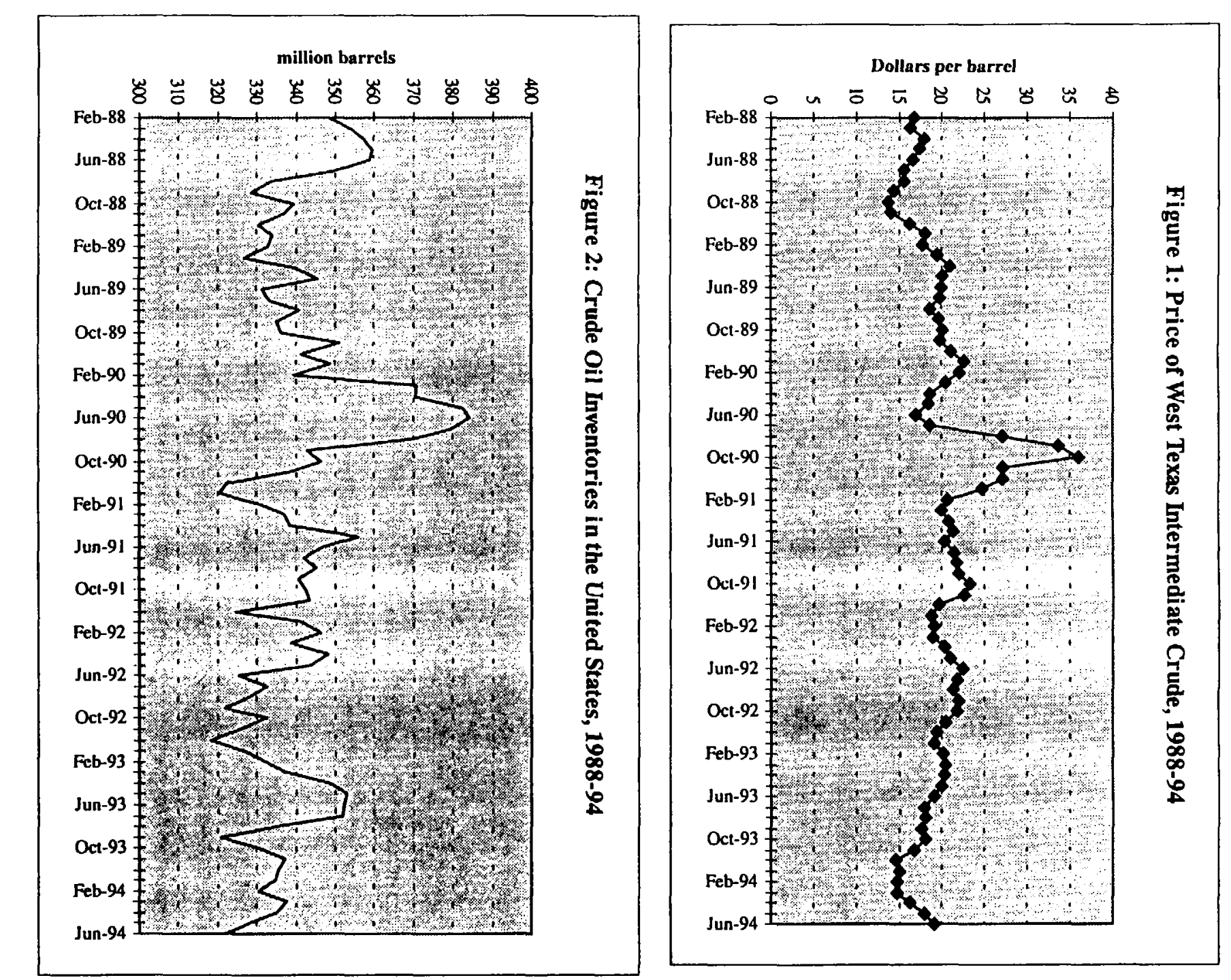

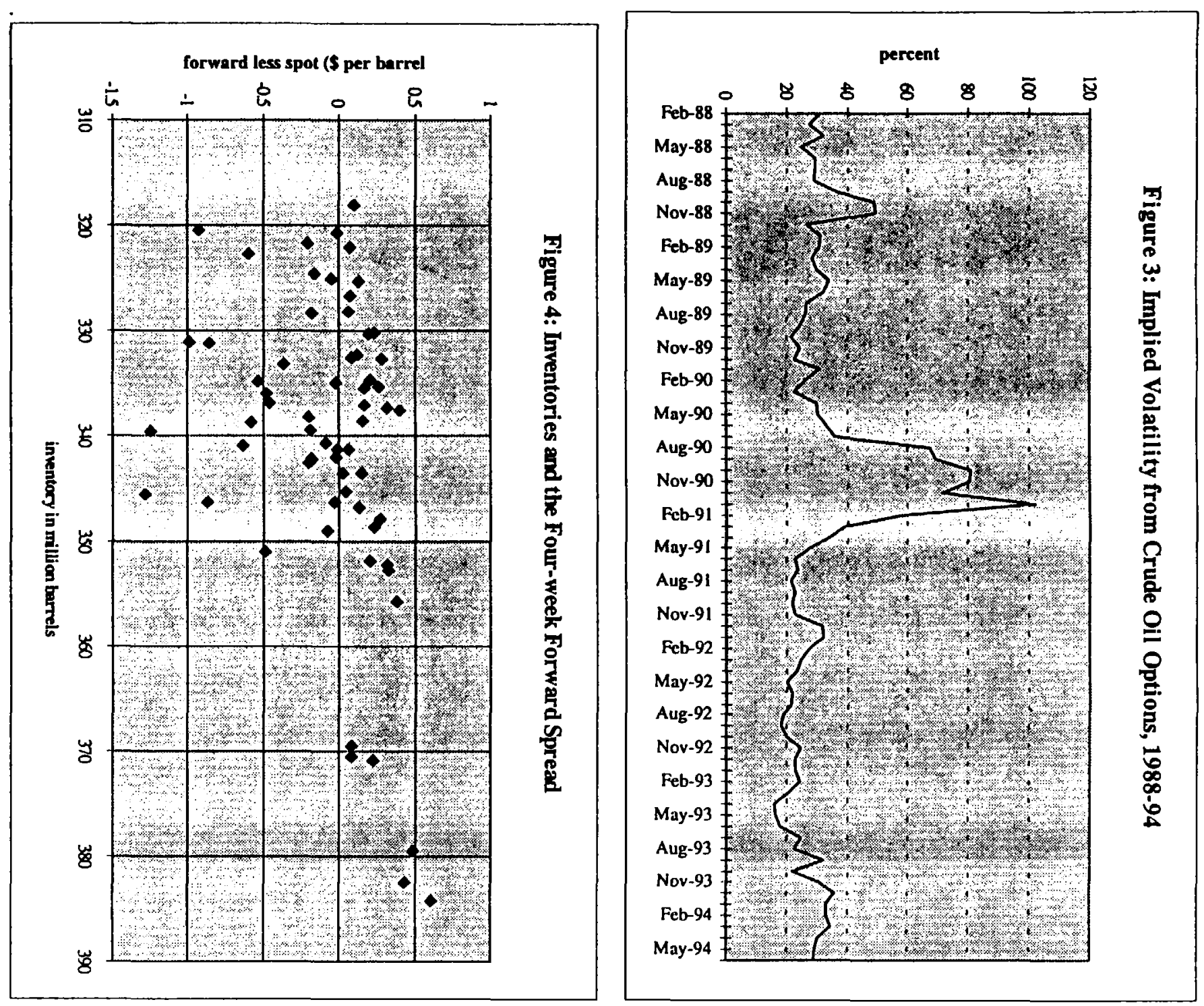

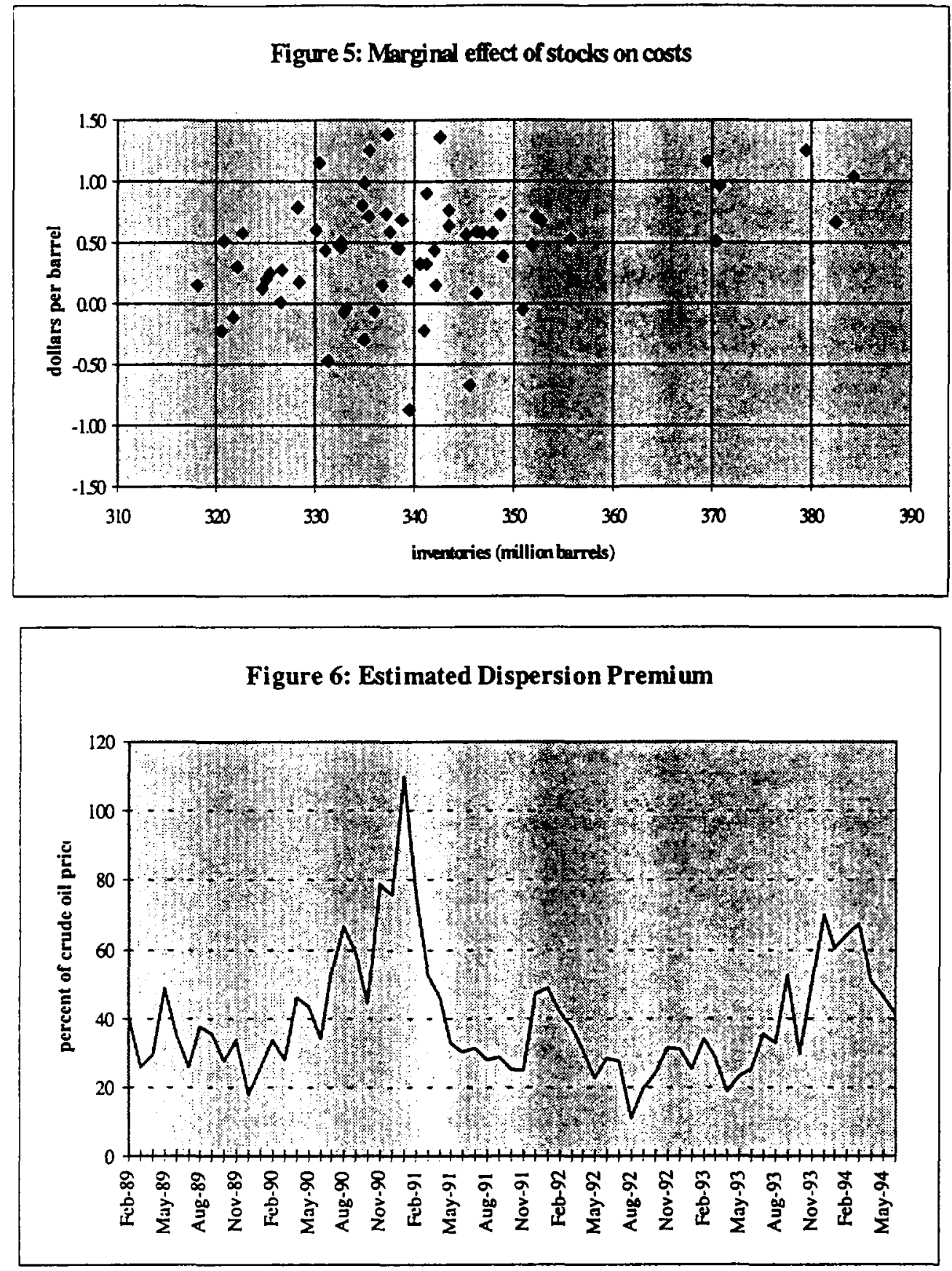


\section{References}

Adelman, M. A. 1990. Mineral Depletion, with Special Reference to Petroleum. The Review of Economics and Statistics. 72(1): 1-10.

Adelman, M. A. and G. C. Watkins 1995 Reserve Asset Values and the Hotelling Valuation principle: Further Evidence. Southern Economic Journal 61(3) 664-672.

Blanchard, Oliver J. 1983. The Production and Inventory Behavior of the American Automobile Industry. Journal of Political Economy: 365-400, June.

Blinder, Alan. 1982. Inventories and Sticky Prices. American Economic Review 72: 334-48.

Blinder, Alan. 1986. Can the Production Smoothing Model of Inventory Behaviour Be Saved? Quarterly Journal of Economics 101: 431-53.

Blinder, Alan S., and Louis J. Maccini. 1991. Taking Stock: A Critical Assessment of Recent Research on Inventories. Journal of Economic Perspectives 5: 73-96.

Brennan, Michael J. 1958. The Supply of Storage. American Economic Review 47: 50-72.

Brennan, Michael J., and E. S. Schwartz. 1985. Evaluating Natural Resource Investments. Journal of Business 58: 135-57.

Considine, Timothy J. 1991. A Short-Run Model of Petroleum Product Supply. The Energy Journal 13: 61-91.

Cootner, Paul 1960 Returns to Speculators: Telser vs. Keynes. Joumal of Political Economy 68: 396 404.

Dixit, Avinash 1990 Optimization in Economic Theory. Oxford: Oxford University Press.

Fair, Ray C. 1989. The Production Smoothing Model is Alive and Well. Journal of Monetary Economics 24: $353-70$.

Gibson, Rajna, and E. S. Schwartz. 1990. Stochastic Convenience Yield and the Pricing of Oil Contingent Claims. The Journal of Finance 45(3): 959-75.

Gibson, Rajna, and E. S. Schwartz. 1989. Valuation of Long Term Oil-Linked Assets, Anderson Graduate School of Management, UCLA, Working Paper, \#6-89.

Heal, Geoffrey, and Michael Barrow. 1980. The Relationship between Interest Rates and Metal Price Movements. Review of Economic Studies 47: 161-81

Hotelling, Harold. 1931 The Economics of Exhaustible Resources. Joumal of Political Economy 39 April: 137-75.

Kaldor, Nicholas. 1939. Speculation and Economic Stability. Review of Economic Studies 7: 1-27. 
Krane, Spencer D., and S. N. Braun. 1991. Production Smoothing Evidence from Physical-Product Data. Journal of Political Economy 99(3): 558-77.

Larson, Donald F. 1993. Copper and the Negative Price of Storage, Policy Research Working Paper 1282, World Bank.

Lovell, Michael C. 1961. Manufacturers' Inventories, Sales Expectations, and the Acceleration Principle. Econometrica 24: 293-314.

Merton, Robert C. 1992. Continuous Time Finance, Cambridge, Massachusetts: Blackwell.

Miller, Merton H. and Charles W. Upton. 1985a A Test of the Hotelling Valuation Principle. Journal of Political Economy 95(1): 1-25.

Miller, Merton H. and Charles W. Upton. 1985b The Pricing of Oil and Gas: Some Further Results. The Journal of Finance 40(3): 1009-1020.

Pindyck, Robert S. 1994. Inventories and the Short-Run Dynamics of Commodity Prices. Rand Journal of Economics 25(1): 141-159.

Smith, V. Kerry. 1981. The Empirical Relevance of Hotelling's Model of Natural Resources. Resources and Energy 3: 105-17.

Telser, Lester G. 1958. Futures Trading and the Storage of Cotton and Wheat. Journal of Political Economy 66: 233-55.

Working, Holbrook. 1934. Theory of Inverse Carrying Charge in Futures Markets. Journal of Farm Economics 30: $1-28$.

Williams, Jeffrey C., and Brian D. Wright. 1991 Storage and Commodity Markets. Cambridge, England:

Cambridge University Press. 

Policy Research Working Paper Series

Title

WPS1638 Private Pension Funds in Hungary: Early Performance and Regulatory Issues

WPS1639 Income Insecurity and Underemployment in Indonesia's Informal Sector

WPS1640 Labor Regulations and Industrial Relations in Indonesia

WPS1641 Poverty and Inequality During Structural Adjustment in Rural Tanzania

WPS1642 Banking Reform in Transition Countries

WPS1643 The Consequences of Doubling the Minimum Wage: The Case of Indonesia

WPS1644 Pricing Industrial Pollution in China: An Econometric Analysis of the Levy System

WPS1645 How Prices and Macroeconomic Policies Affect Agricultural Supply and the Environment

WPS1646 Budgetary Institutions and Expenditure Outcomes: Binding Governments to Fiscal Performance

WPS1647 The Baltics-Banking Crises Observed

WPS1648 The Lender of Last Resort Function Under a Currency Board: The Case of Argentina

WPS1649 Economic Regulation of Water Companies

WPS1650 Bank-Led Restructuring in Poland: An Empirical Look at the Bank Conciliation Process
Author Date

Dimitri Vittas

August 1996

Contact

for paper

P. Infante

37642

Franck Wiebe

August 1996

J. Israel

85117

Alejandra Cox Edwards

August 1996

M. Mclntosh-Alberts 33750

M. Luisa Ferreira

August 1996

H. Taddese 31086

Stijn Claessiens

Martin Rama

Hua Wang

David Wheeler

Nlandu Mamingi

Ed Campos

Sanjay Pradhan

Alex Fleming

Lily Chu

Marie-Renée Bakker

Gerard Caprio, Jr.

Michael Dooley

Danny Leipziger

Carl Walsh

Michael Klein

Cheryl W. Gray

Arnold Holle
August 1996

September 1996

September 1996

H. Wang

33255

September 1996

A. Williams

37176

September 1996

C Bernardo 31148

September 1996

S. Coffey 32635

September 1996

B. Moore 38526

September 199

S. Vivas 82809

September 1996

B. Moore 38526 


\section{Policy Research Working Paper Series}

\begin{tabular}{|c|c|c|c|c|}
\hline & Title & Author & Date & $\begin{array}{l}\text { Contact } \\
\text { for paper }\end{array}$ \\
\hline WPS 1651 & $\begin{array}{l}\text { Bank-Led Restructuring in Poland: } \\
\text { Bankruptcy and Its Alternatives }\end{array}$ & $\begin{array}{l}\text { Cheryl W. Gray } \\
\text { Arnold Holle }\end{array}$ & September 1996 & $\begin{array}{l}\text { B. Moore } \\
38526\end{array}$ \\
\hline WPS1652 & $\begin{array}{l}\text { Intra-Industry Trade, Foreign Direct } \\
\text { Investment, and the Reorientation } \\
\text { of Eastern European Exports }\end{array}$ & $\begin{array}{l}\text { Bernard Hoekman } \\
\text { Simeon Djankov }\end{array}$ & September 1996 & $\begin{array}{l}\text { F. Hatab } \\
35853\end{array}$ \\
\hline WPS1653 & $\begin{array}{l}\text { Grants and Debt Forgiveness in } \\
\text { Africa: A Descriptive Analysis }\end{array}$ & Leonardo Hernández & & \\
\hline WPS1654 & Indonesia's Palm Oil Subsector & Donald F. Larson & September 1996 & $\begin{array}{l}\text { P. Kokila } \\
33716\end{array}$ \\
\hline WPS1655 & $\begin{array}{l}\text { Uncertainty and the Price for Crude } \\
\text { Oil Reserves }\end{array}$ & $\begin{array}{l}\text { Timothy J. Considine } \\
\text { Donald F. Larson }\end{array}$ & September 1996 & $\begin{array}{l}\text { P. Kokila } \\
33716\end{array}$ \\
\hline
\end{tabular}

